〈Research Paper〉

\title{
Spectral Properties of a pH Responsive Water Soluble Spironaphthoxazine and Its Multi-Switching Property
}

\author{
Jin-Seok Bae and Sung-Hoon Kim ${ }^{\dagger}$ \\ Department of Textile System Engineering, Kyungpook National University, Daegu, Korea
}

(Received: February 21, 2013 / Revised: March 4, 2013 / Accepted: March 5, 2013)

\begin{abstract}
A water soluble spironaphthoxazine (SPO) was synthesized, and its spectral properties were determined. Under UV irradiation, colorless SPO shows intensive blue color while the intensity of its initial fluorescence decreased. In addition, SPO also exhibited high sensitivity to $\mathrm{pH}$ stimuli both in colorimetry and fluorometry distinguishing from the spectral appearance observed under UV irradiation. Further, integrating these two optical characteristics a three-state switching system can be established, and all interconversions can be observed by naked-eye.
\end{abstract}

Keywords: water soluble spironaphthoxazine, colorimetric, fluorometric, pH stimulation, multi-switching

\section{Introduction}

Spironaphthoxazines (SPO), a promising family of photochromic compounds, has already been gained continuous attention for last three decades due to their supereminent fatigue-resistance properties ${ }^{1-3)}$. Many systematic studies on SPO have been reported ${ }^{4-7)}$, and following that ten thousands of SPO derivatives were synthesize and published aiming on the improvement of chemical or physical natures of parent $\mathrm{SPO}^{8,9)}$ or the extension of application ${ }^{10)}$. Among these works, water soluble SPO is an interesting series of SPO derivatives from manufacture of photochromic LBL (layer-by-layer) film which is a kind of organic ultrathin film applying in various fields ${ }^{11,12)}$. However, for other application few papers of ionic SPO have been reported.

We herein reported a novel cationic SPO showing reversibly spectral changes by modulation with $\mathrm{pH}$ stimuli both in colorimetry and fluorometry. The colorless SPO showed an intensive blue color when upon UV irradiation accompanied with the decrease of initial intensity of fluorescence. In order to improve an essential demerit of SPO as lacking water-solubility which strictly limits its application in

${ }^{\dagger}$ Corresponding author: Sung-Hoon Kim (shokim@knu.ac.kr) Tel.: +82-53-950-5641 Fax.: +82-53-950-6617

(c) 2013 KSDF 1229-0033/2013-03/18-24 some extent, SPO molecule was converted into ionic configuration by anchoring two quaternary ammonium groups to SPO matrix with a triazinyl. And as we expected, this transformation dramatically enhance the solubility of SPO in water phase.

In this paper, we described the synthesis of cationic SPO and determined its spectral properties when under $\mathrm{UV}-\mathrm{Vis}$. irradiation as well as $\mathrm{pH}$ stimuli. And multi -switching behavior was also expatiated.

\section{Experimental}

\subsection{Materials and Instruments}

1,3,3-trimethyl-2-methyleneindoline (Fisher's base), 2,7dihydroxynaphthlene, cyanuric chloride, $N, N, N^{\prime}, N^{\prime}$-tetramethyl-1,3-propanediamine, were purchased from Aldrich Chemical Company. Compound 1 was obtained by synthesis according to the literature methods ${ }^{13,14)}$.

Compound 4 was synthesized by following the method reported previously ${ }^{11,12)}$. All chemicals were of the highest grade available and were used without further purification. Melting points were determined to use an Electrothermal IA 900 and are uncorrected.

Absorption spectra were measured with an Agilent 8453 spectrophotometer. Fluorescence spectra were measured on a Shimadzu RF-5310PC fluorescence spectrophotometer. IR spectra were measured with a Spectrum GX \& Auto Imaging IR Spectrometer. A 
high pressure mercury lamp (Ushio, SP3-250D) was used as the UV irradiation source and calibrated with a monochromator at $366 \mathrm{~nm}$.

\subsection{Synthesis}

\subsubsection{Synthesis of compound 3}

Cyanuirc chloride 2 (6.61g, 35.85mmol) was dissolved in $120 \mathrm{ml}$ of acetone. Temperature of the solution was maintained at $0-5^{\circ} \mathrm{C}$. The prepared compound 1 $(12.33 \mathrm{~g}, 35.85 \mathrm{mmol})$ was added into the solution, which was then stirred for $2.5 \mathrm{~h} . \mathrm{Na}_{2} \mathrm{CO}_{3}(40 \mathrm{ml}, 0.98 \mathrm{~N})$ was added into the solution and stirred for $1.5 \mathrm{~h}$. After completion of reaction, the solution was poured into $500 \mathrm{ml}$ of $\mathrm{H}_{2} \mathrm{O}$. The resulting solid 3 was filtered and obtained.

Yield: $13.3 \mathrm{~g}(75 \%)$; m.p.: $140^{\circ} \mathrm{C}$; MS m/z $\left(\mathrm{M}^{+}\right) 492$; Anal. calc. for $\mathrm{C}_{25} \mathrm{H}_{19} \mathrm{Cl}_{2} \mathrm{~N}_{5} \mathrm{O}_{2}: \mathrm{C}, 60.99 ; \mathrm{H}, 3.89 ; \mathrm{N}$, 14.22; Found: C, 60.01; H, 3.76; N, 14.13.

\subsubsection{Synthesis of SPO}

The compound $3(0.5 \mathrm{~g}, 1 \mathrm{mmol})$ and compound 4 $(0.27 \mathrm{~g}, 2 \mathrm{mmol})$ were dissolved in acetonitrile solution $(20 \mathrm{ml})$. The mixture solution was stirred for $5 \mathrm{~h}$ at room temperature. After the reaction finished, the mixture solution was poured into $100 \mathrm{ml}$ ether and precipitated; then filtered and washed with ether and ethyl acetate by 3 times, respectively. The SPO was obtained and dried at $60^{\circ} \mathrm{C}$ in vacuum for $12 \mathrm{~h}$.

Yield: $33 \%$; m.p.: $256^{\circ} \mathrm{C}$

IR (KBr, disc): v=3420, 2958, 2596, 2481， 1616, 1484, 1387, 1304, 1253, 1208, 1085, 957, 821, 743

TGA: $346.47^{\circ} \mathrm{C}$

\section{Results and Discussions}

\subsection{Spectral properties of SPO}

The photochromic reaction was caused by the reversible heterolytic cleavage of the $\mathrm{C}$ (spiro)-O bond under UV irradiation, yielding the colored form that can return to the colorless form by ring closure under visible light irradiation or in the dark ${ }^{15,16)}$. Photochromic behavior of SPO in water is depicted as Figure 1.

Under UV irradiation, the SPO showed an intensive absorption band centered at $598 \mathrm{~nm}$ referring to the heterolytic dissociation of $\mathrm{C}-\mathrm{N}$ from the photochromic component, producing colored open merocyanine ${ }^{17,18)}$.

Comparing to parent compound 1, the open form of SPO presented a slight bathochromic shift arising from electron-withdrawing property of two quaternary ammonium groups at tertramethylpropanediamine moiety ${ }^{19)}$. After removing the irradiation source, the absorption maximum decreased as the open merocyanine reversibly

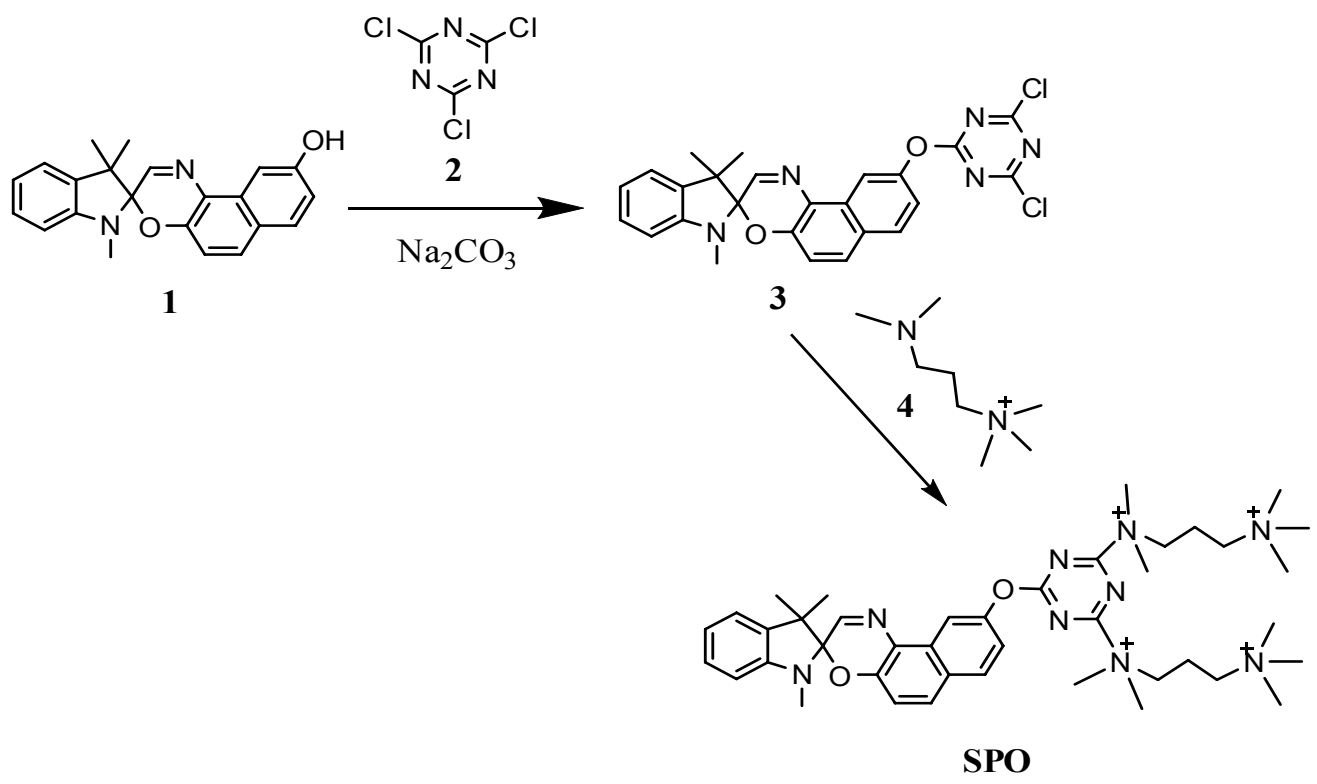

Scheme 1. Synthesis of SPO 


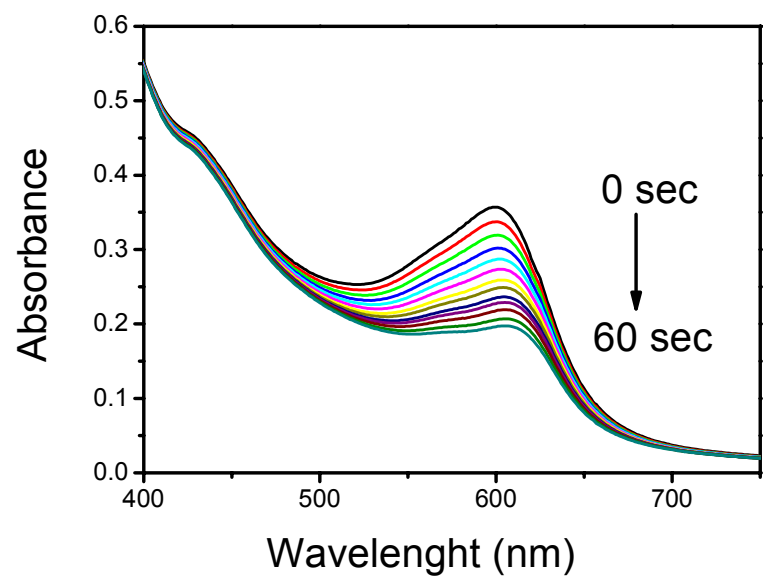

Figure 1. Spectral changes of SPO after UV irradiation for $1 \mathrm{~min}$ in water $\left(1 \times 10^{-5} \mathrm{~mol} / \mathrm{L}\right)$.

convert into closed spiro from. The spectral measurements after UV irradiation are at any time proportional to each other in the visible region, indicating that only one species was formed. Meanwhile initial SPO showed a broad emission band ranged from 400 to $600 \mathrm{~nm}$ (see Figure 2).

\subsection{Acid-base switchable behavior of SPO}

\subsubsection{Acid-base effects on absorption spectra}

Upon the addition of $\mathrm{H}^{+}$, a distinct absorption band appeared in the visible region.

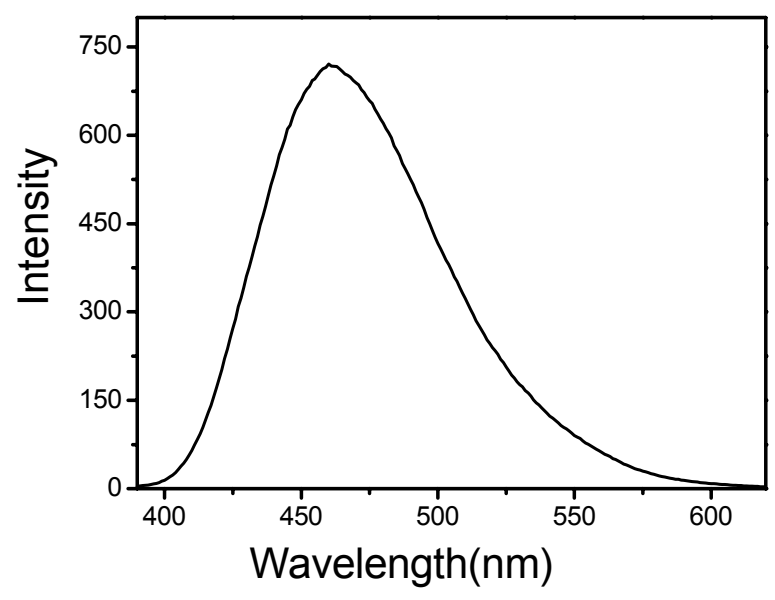

Figure 2. Emission spectrum of SPO when excited with wavelength of $370 \mathrm{~nm}$.

The measurement was performed in SPO dissolved water solution titrating with hydrogen chloride. The absorbance gradually increased along with increasing the concentration of hydrogen chloride. Distinct from photoinduced course, the new absorption bands arose round 430nm (see Figure 3), leading to a yellow color. This change related to the intrinsic nature of SPO, namely heterolytic cleavage in acidic environment and the subsequent protonation of the merocyanine $\mathrm{MEH}^{20)}$ (see Scheme 2). After addition of equivalent $n$-tetrabutylammonium hydroxied, the spectral pattern recovered due<smiles>CN(CCC[N+](C)(C)C)c1nc(Oc2ccc3ccc4c(c3c2)N=CC2(O4)N(C)c3ccccc3C2(C)C)nc([N+](C)(C)CCC[N+](C)(C)N(C)C)n1</smiles><smiles>C=[AsH3]</smiles>

SPO

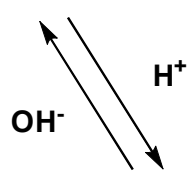

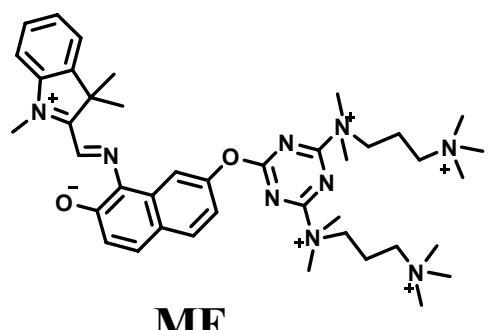

ME

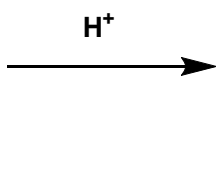

MEH

Scheme 2. The reversible interconversion of three states of SPO 


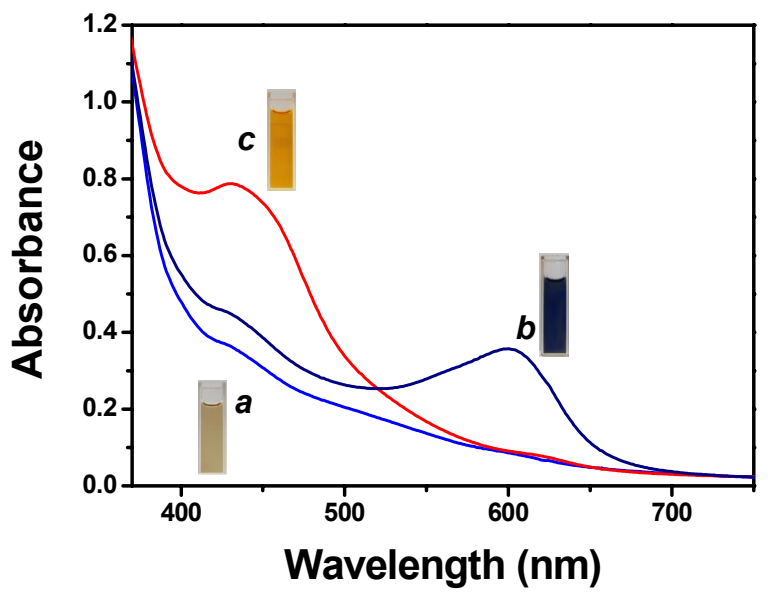

Figure 3. (a) Absorption spectra of SPO, (b) ME, (c) MEH.

to the reisomerization from the protonated open merocyanine MEH to initial spiro form SPO.

Meigong Sun et $a l^{20)}$ reported that parent photochromic spironaphthoxazines also exhibit acidichromic behaviors, where in the photonated open merocyanine gradually discolored when the solution were stored in the dark. The intensity of the absorbance of colored merocyanine $\mathrm{MEH}$, however, was found with no variation in the dark condition. Moreover, the protonated $\mathrm{MEH}$ did not only show no sensitivity to photoirradiation, but also to thermal change, indicating that form MEH offers good photostability and thermostability. The interconversion from SPO to MEH can only be modulated by the adjustment of the concentration of $\mathrm{H}^{+}$.

\subsubsection{Multi-switching system}

Associating with change induced by UV/vis irradiation, a three-state switching system can be developed on the basis of reversible interconversion of SPO.

SPO ring opens upon ultraviolet irradiation to generate the merocyanine ME. This transformation is accompanied with the appearance of an intensive absorption band in the visible region (Figure 3). There transformation of merocyanine ME to the original spiro form is thermodynamically forbidden when only treated with heating, indicating that the open form ME offers a good thermostability. In the presence of acid, however, ME switches to $\mathrm{MEH}$ with remarkable changes on the absorption spectra (Figure 3). The protonated merocyanine $\mathrm{MEH}$ can also be generated directly from SPO after the addition of acid. Furthermore, the protonated species MEH switches to SPO only upon addition of base, providing good thermo- and photostability. Thus, the reversible interconversion of the three states SPO, ME and $\mathrm{MEH}$ can be established by cooperating UV-vis irradiation and $\mathrm{pH}$ stimuli.

\subsubsection{Acid-base effects on fluorescent spectra}

The interconversion from SPO to MEH also resulted in changes on emission spectra illustrated in Figure 4.

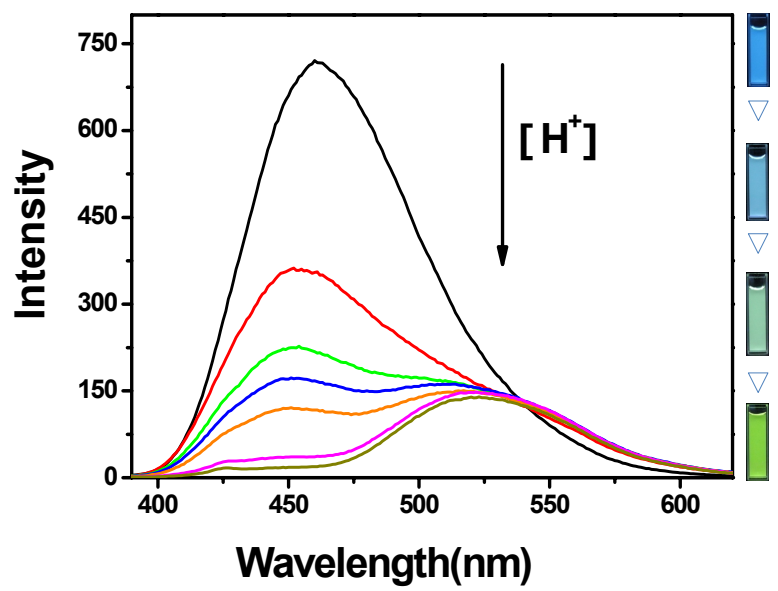

Figure 4. Emission spectral changes of SPO upon addition of $\mathrm{HCl}$ and n-tetrabutylammonium hydroxied in turn (in water).

As the data shown in Table 1, in the presence of low concentration of $\mathrm{H}^{+}\left(3 \times 10^{-2} \mathrm{M}\right)$ the intensity of fluorescence approximately deceases to a half and the emission bands slightly shift to short wavelength region, referring to the heterolytic cleavage of photochromic component (Scheme 2). When the concentration of $\mathrm{H}^{+}$ increased to $6 \times 10^{-2} \mathrm{M}$, the decrease of intensity round $452 \mathrm{~nm}$ was accompanied with the appearance of a new emission band centered round $525 \mathrm{~nm}$, indicating that the open MEH was protonated. Subsequently increasing the ratio, the intensity of former emission bands declined and totally disappeared in a high concentration of $\mathrm{H}^{+}$ $\left(>30 \times 10^{-2} \mathrm{M}\right)$ as well as the intensity of new one almost presented no more ascents. 
Table 1. Emission spectra changes with addition of $\mathrm{H}^{+}$into water solution of SPO (dye $\left.=3 \times 10^{-5} \mathrm{~mol}\right)$

\begin{tabular}{|c|c|c|}
\hline Concentration of $\mathrm{H}^{+}(\mathrm{M})$ & $\lambda_{\text {em }}(\mathrm{nm})$ & Intensity \\
\hline 0 & $\lambda_{\mathrm{em}}=460$ & $\mathrm{I}=720$ \\
\hline $3 \times 10^{-2}$ & $\lambda_{\mathrm{em}}=452$ & $I=362.16$ \\
\hline $6 \times 10^{-2}$ & $\lambda_{\mathrm{em} 1}=452 ; \lambda_{\mathrm{em} 2}=522$ & $\mathrm{I}_{1}=225 ; \mathrm{I}_{2}=154.8$ \\
\hline $9 \times 10^{-2}$ & $\lambda_{\mathrm{em} 1}=452 ; \lambda_{\mathrm{em} 2}=522$ & $I_{1}=171 ; \quad I_{2}=155.7$ \\
\hline $12 \times 10^{-2}$ & $\lambda_{\mathrm{em} 1-}=452 ; \lambda_{\mathrm{em} 2}=522$ & $I_{1}=119.3 ; \quad I_{2}=1477.7$ \\
\hline $30 \times 10^{-2}$ & $\lambda_{\mathrm{em}}=522$ & $\mathrm{I}=148$ \\
\hline $45 \times 10^{-2}$ & $\lambda_{\mathrm{em}}=522$ & $\mathrm{I}=140$ \\
\hline
\end{tabular}

$* \lambda_{\mathrm{ex}}=370 \mathrm{~nm}$

The emission response of $\mathrm{SPO}$ to $\mathrm{H}^{+}$over a wide concentration range is shown in Figure 5. The original blue emission of SPO is changed to light blue in the presence of low concentrations of $\mathrm{H}^{+}\left(3 \times 10^{-2} \sim 9 \times 10^{-2}\right.$ $\mathrm{M})$, and in turn subsequently changed to cyan to green in the high concentration region $\left(3.0 \times 10^{-2} \mathrm{M}\right)$.

The CIE chromaticity diagram (CIE=International Commission on Illumination) for the emission of SPO at various concentrations of $\mathrm{H}^{+}$demonstrates the fine -tuning of the emission color from blue to green in response to $\mathrm{H}^{+}$concentration (Figure 5).

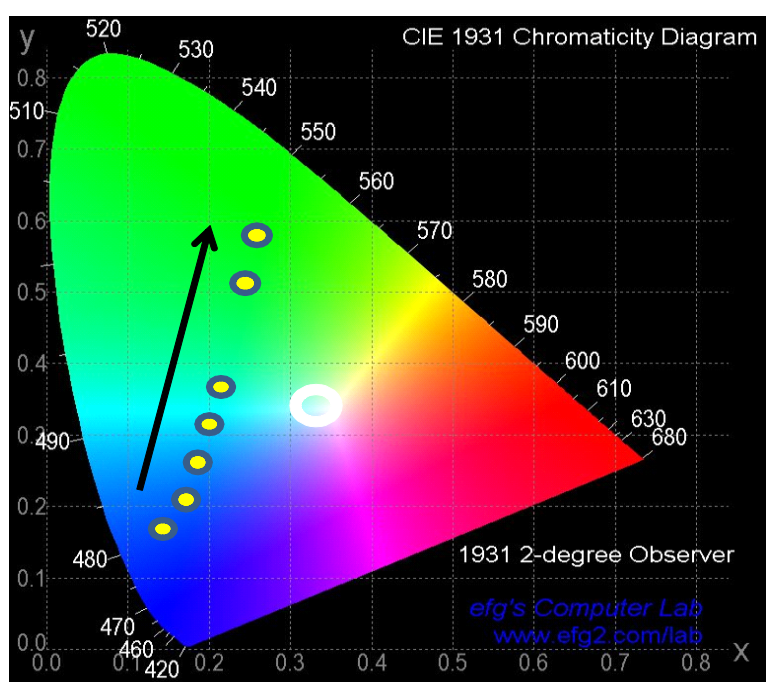

Figure 5. CIE chromaticity diagram for the emission of SPO $\left(3.0 \times 10^{-5} \mathrm{~mol}\right)$ in the presence of $\mathrm{H}^{+}$in water at 293K.

In the context of the ability of SPO to function as a gas detector, when a TLC plate adsorbed with SPO was exposed to $\mathrm{HCl}$ and ethylamine vapour in turn, marked change of fluorescence emission occurred (Figure 6).

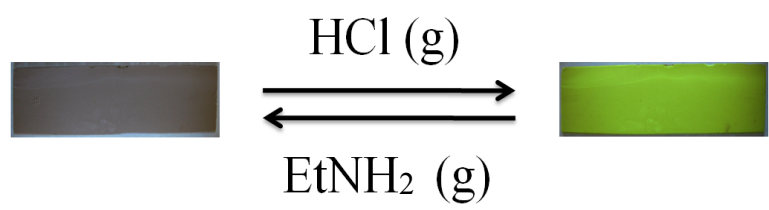

Figure 6. Fluorescence changes observed for SPO imparted by exposure to $\mathrm{HCl} / \mathrm{EtNH}_{2}$ vapour.

It is apparent that upon exposure to $\mathrm{HCl}$ vapour, the change in fluorescent color obtained was visually noticeable; when the TLC plate which had been exposed to the $\mathrm{HCl}$ vapour was exposed to ethylamine vapour, the original state was regenerated within $1 \mathrm{~s}$ as response time of fluorescent reversal. These reversible phenomena were repeated several times for a given TLC plate adsorbed with SPO.

\section{Conclusion}

The emission spectra and acid-base switchable behavior of SPO were investigated. The SPO exhibited blue fluorescence in water solution. In the presence of $\mathrm{H}^{+}$ the SPO underwent heterolytic cleavage converting to an open merocyanine form, resulting in generating a distinct absorption bands from those observed by UV irradiation. And their intensity of fluorescence of SPO can be modulated by either photochromism or acidichromism. Fluorescence in turns changed from cyan to green. Both absorption and emission spectral changes can be restored by addition equivalent $n$-tetrabutylammonium hydroxied. Thus, three-states molecular switching modulated by acid-base and electromagnetic irradiation is realized and expected to show its potential in application. 


\section{Acknowledgement}

This work was supported by Basic Science Research Program through the National Research Foundation of Korea (NRF) funded by the Ministry of Education, Science and Technology (2010-0008738). This research was supported by Kyungpook National University Research Fund, 2012.

\section{Reference}

1. H. Durr and H. Bouas-Laurent, "Photochromism, Molecules and Systems", Elsevier, Amsterdam, 1990.

2. C. Bohne, M. G. Fan, Z. J. Li, Y. C. Liang, J. Lusztyk, and J. C. Scaiano, Laser Photolysis Studies of Photochromic Processes in Spirooxazines : Solvent Effects on Photomerocyanine Behavior, Journal of Photochemistry and Photobiology A: Chemistry, 66(1), 79(1992).

3. X. Y. Zhang, S. Jin, Y. F. Ming, Y. C. Liang, L. H. Yu, M. G. Fan, J. Luo, Z. H. Zuo, and S. D. Yao, Substituent Effect on Photochromism of Indolinospirooxazines, Journal of Photochemistry and Photobiology A: Chemistry, 80(3), 221(1994).

4. R. J. Hovey, N. Y. C. Chu, P. G. Piusz, and C. H. Fuchsman, US Pat. 4215010(1980).

5. J. Hobley and F. Wilkinson, Photochromism of Naphthoxazine-spiro-indolines by Direct Excitation and Following Sensitization by Triplet-energy Donors, Journal of the Chemical Society, Faraday Transactions, 92(8), 1323(1996).

6. N. Y. C. Chu, US Pat. 4699473(1987).

7. M. Rickwood, S. D. Marsden, M. E. Ormsby, A. L. Staunton, and D. W. Wood, Red Coloring Rhotochromic 6'-substituted Spiroindolinonaphth[2,1b][1,4] Oxazines, Molecular Crystals and Liquid Crystals Science and Technology Section A: Molecular Crystals and Liquid Crystals, 246(1), 17(1994).

8. X. L. Meng, W. H. Zhu, Z. Q. Guo, J. Q. Wang, and H. Tian, Highly Stable and Fluorescent Switching Spirooxazines, Tetrahedron, 42(6), 9840(2006).

9. C. R. Zhang, Z. B. Zhang, M. G. Fan, and W. P. Yan, Positive and Negative Photochromism of
Novel Spiro[indoline-phenanthrolinoxazines], Dyes and Pigments, 76(3), 832(2008).

10. H. Tian, B. Qin, R. X. Yao, X. L. Zhao, and S. J. Yang, A Single Photochromic Molecular Switch with Four Optical Outputs Probing Four Inputs, Advanced Materials(Weinheim, Germany), 15(24), 2104(2003).

11. S. H. Kim, C. J. Shin, S. R. Keum, and K. N. Koh, Layer-by-layerself-assembled Multilayer of Cationic Spiroxazine and Polystyrenesulfonate, Dyes and Pigments, 72(3), 378(2007).

12. S. H. Kim, C. Y. Yu, C. J. Shin, and M. S. Choi, Photochromiclayer-by-layer films of Spiroxazine Polymer, Dyes and Pigments, 75(1), 250(2007).

13. T. Kakishita, K. Matsumoto, T. Kiyotsukuri, K. Matsumura, and M. Hosoda, Synthesis and NMR Study of 9'-substituted Spiroindolinonaphthoxazine Derivatives, Journal of Heterocyclic Chemistry, 29(7), 1709(1992).

14. H. Durr, Y. M. Ma, and G. Cortellaro, Preparation of Photochromic Molecules with Polymerizable Organic Functionalities, Synthesis, 3, 294(1995).

15. Y. Son and J. Park, Rhodamine 6G Based New Fluorophore Chemosensor Toward $\mathrm{Hg}^{2+}$, Textile Coloration and Finishing(J. Korean Soc. Dye. and Finish.), 24(3), 158(2012).

16. H. Kim and Y. Son, Synthesis and Optical Properties of Novel Chemosensor Based on Rhodamine 6G, Textile Coloration and Finishing(J. Korean Soc. Dye. and Finish.), 24(4), 233(2012).

17. H. Nishikiori, N. Tanaka, K. Takagi, and $T$ Fujii, Solvent Effect on Fluorescence Spectra of a Spirooxazine, Research on Chemical Intermediates, 29(5), 485(2003).

18. S. Kawauchi, H. Yoshida, N. Yamashina, M. Ohira, S. Saeda, and M. Irie, A New Photochromic Spiro [3H-1,4-oxazine], Bulletin of Chemical Society of Japan, 63(1), 267(1990).

19. H. H. Tang, H. Xing, W. H. Huang, and F. Zhang, Two-photon Three-dimensional Optical Data Storage with Equal Exposure Energy and Time Increase, Guangxue Xuebao, 29(5), 134751(2009). 
20. X. D. Sun, M. G. Fan, X. J. Meng, and E. T. Knobbe, Acidichromic Effects in Spiro(1,3,3-trimethy lindolo-2,3'-naphth[1,2-b]-1,4-oxazine), a Photochromic
Compound I: Absorption Characteristics, Journal of Photochemistry and Photobiology A: Chemistry, 102(3), 213(1997). 